\title{
Congenital Dislocation of the Hip in Children between the Ages of One and Three: Open Reduction and Modified Salter Innominate Osteotomy Combined with Fibular Allograft
}

\author{
Nguyen Ngoc Hung \\ National Hospital of Pediatrics of Vietnam, Hanoi, Vietnam. \\ Email: ngocyenhung@gmail.com \\ Received April 28 $8^{\text {th }}, 2013$; revised May 29 ${ }^{\text {th }}, 2013$; accepted June $5^{\text {th }}, 2013$ \\ Copyright (c) 2013 Nguyen Ngoc Hung. This is an open access article distributed under the Creative Commons Attribution License, \\ which permits unrestricted use, distribution, and reproduction in any medium, provided the original work is properly cited.
}

\begin{abstract}
Background: Innominate osteotomy procedures have been widely used as an integral component of combined surgery to treat developmental dysplasia of the hip in children. Autograft concern is further supported by authors who suggest the routine use of internal fixation. Problems such as graft extrusion, rotation and absorption, leading to loss of acetabular correction, were often noted in cases previously treated at our National Hospital for Pediatrics. This retrospective study reviewed the radiographic results of this treatment protocol in 106 hips developmental dislocated hips which met our inclusion criteria. The efficacy of this method to achieve and maintain a well covered and stable hip was the main objective of the study. Methods: This retrospective study reviewed the radiographs of 106 hips presenting with developmental dislocation which were treated by modified Salter's innomiate osteotomy and using a fibular allograft as the interposition material. Dislocations of the hip were graded using the Tönnis system. Measurement of the acetabular index (AI) was the main variable. The minimum follow up period was 2 years. Possible complications such as loss of acetabular correction, hip redislocation, graft extrusion or resorption, the need for osteotomy internal fixation, delayed or non union, infection or avascular necrosis (AVN) were documented in this series. Results: Between January 2004 and December 2008, 106 surgeries were performed in 95 patients. Sixty-three (86.3\%) of the patients were girls and ten $(13.7 \%)$ were boys, thirteen patients (13.7\%) were between twelve and eighteen months old at the time of the operation, the remaining eighty-two (86.3\%) patients being between eighteen and thirty-six months old, with the mean age of 22.6 months at the time of surgery. There were eleven (11.6\%) patients who had bilateral dislocation. Eighty-four (88.4\%) patients were affected unilaterally. The right hip was involved in seventeen (17.9\%) and the left hip in sixty-seven (70.5\%) cases. Tönnis system Type 3 was in 34 hip (32.1\%), and Type 4 was in 72 hip (67.9\%). All patients combined open reduction and modified Salter's innomiate osteotomy, inserting a fibular allograft as the interposition material. Acetabular index was improved, preoperation was $42.95^{\circ}$, and latest follow-up $19.15^{\circ}$, concentrical acetabulum 93.7\%. All of the fibulat allografts were completely incorporated mean 14 weeks (range, 12 weeks - 17 weeks) post-surgery. There were five (4.7\%) redislocation and subluxation, three AVN (2.8\%) and five (4.7\%) coxa magna Without graft infections, none of the osteotomies required internal fixation for stability. Final results: Excellent 70 (66.0\%), Good 29 (27.4\%), Fair 2 (1.9\%), Poor 5 (4.7\%). Conclusion: Open reduction and modified Salter's innomiate osteotomy allow interposition material by fibular allografting with a short operative incision, renders excellent osteotomy stability that eliminates the need for internal fixation. Surgical technique are safe and effective for Children between twelve and thirty-six months old.
\end{abstract}

Keywords: Hip Dysplasia; Innominate Osteotomy; Congenital Dislocation of the Hip; Development Dysplasia of the Hip; Allograft

\section{Introduction}

Developmental dysplasia of the hip (DDH) is an abnormal formation of the hip joint occurring between or- ganogenesis and maturity as a result of instability. Early diagnosis and treatment of DDH is of greatest importance, to get a more favorable prognosis for such a con- 
dition. Moreover, the pathologic changes in patients with DDH are the basis for understanding DDH as a spectrum in time and severity $[1,2]$. Treatment for developmental dysplasia of the hip (DDH) is early reduction and stabilization of the joint to restore physiological joint development. Although closed reduction has been recommended as the first-line treatment modality, one study found that $66 \%$ of patients required secondary surgery for residual dysplasia [3]. Salter described an innominate osteotomy that redirects the acetabulum to correct hip dysplasia and reported good or excellent radiographic results in $92 \%$ of patients [4].

Open reduction is generally indicated in developmental dysplasia of the hip (DDH) when a stable, concentric reduction cannot be achieved by closed means. Although this procedure is largely successful in obtaining an adequate reduction, failures, including redislocation, can and do occur. Open reduction of the hip and Salter's osteotomy have become a popular procedure in treating late presenting DDH in a single attempt $[5,6]$. These failures remain a challenging clinical problem as revision surgery has been associated with high rates of stiffness, residual dysplasia, and avascular necrosis (AVN) $[7,8]$.

Treatment of children older than 12 months with a hip dislocation is more challenging. In addition, older children need primary acetabular reorientation osteotomy, such as Salter or Pemberton procedures to adequately cover the femoral head $[9,10]$. The treatment of congenital dislocation of the hip in the older patient who has begun to walk is difficult because of adaptive shortening of the extra-articular soft tissues, acetabular dysplasia, capsular constriction, increased fernoral anteversion, and fixed inversion of the limbs [11,12].

The authors have over the years, not been satisfied that iliac crest autograft as the interposition material for the osteotomy is structurally sound and sufficiently stable. Problems such as graft extrusion, rotation and absorption, leading to loss of acetabular correction, were often noted in cases previously treated at the National Hospital for Pediatrics. Autograft concern is further supported by authors who suggest the routine use of internal fixation, especially in older children. Bone allografts have commonly been used in orthopaedic practice, and in particular, in paediatric orthopaedic surgery with good safety and efficacy [13].

The purpose of this paper is to review our experience with the management of congenital dislocation of the hip in children in whom treatment was not begun until between the ages of one and three years with open reduction and modified Salter innominate osteotomy combined fibular allograft. Based on this experience, a safe and effective approach to this problem will be presented.

\section{Material and Methods}

\subsection{Patient and Hip Classification and Measurement}

Patient Selection: This study only included children with $\mathrm{DDH}$, aged twelve to forty-eight months at the time of surgery, and who underwent a one-stage open reduction with modified Salter's innominate osteotomy (MSIO), and fibular allografting. Children within the same age group with a past history of failed conservative included. A minimum follow-up period of 2 year postoperative at the time of the last follow-up control visit was needed for inclusion in this study.

The exclusion criteria were acetabular dysplasia without dislocation, revision surgery for DDH and dislocated hips associated with neuromuscular disease or teratologic conditions, hip condition was secondary to other conditions such as arthrogryposis multiplex congenital, were excluded from this study.

Operative therapy is generally not indicated in patients who are less than one year old, since nonoperative methods are usually successful [14]. Patients who are older than three years pose unique and more serious problems because of the decreased remodeling ability of the hip, and data on such patients are not reported here.

Dislocations of the hip were graded using the Tönnis system [15].

Classification of hip dysplasia according to Tönnis [15].

\begin{tabular}{|c|c|}
\hline Grade & Criteria \\
\hline 1 & Capital femoral epiphysis medial to Perkins line \\
\hline 2 & $\begin{array}{l}\text { Capital femoral epiphysis lateral to Perkins line but below } \\
\text { the level of the superior acetabular rim }\end{array}$ \\
\hline 3 & $\begin{array}{l}\text { Capital femoral epiphysis at the level of the superior } \\
\text { acetabular rim }\end{array}$ \\
\hline 4 & $\begin{array}{l}\text { Capital femoral epiphysis above the level of the superior } \\
\text { acetabular rim }\end{array}$ \\
\hline
\end{tabular}

\subsection{The Acetabular Index Angle}

The acetabular index was measured as the main variable to evaluate the correction of the acetabular dysplasia and the subsequent maintenance thereof. The term acetabular index was introduced by Kleinberg and Lieberman of New York in 1936 to mane a radiograohic sign [16]. "The angle formed between the roof or iliac portion of the acetabulum and a horizontal line passing through the triradiate cartilages."

Normal acetabular index (cf. Figure 1).

The AI was measured pre-operatively, immediate postoperatively and at 3 months, 6 months, 1 year, 2 years, and latest follow-up. 


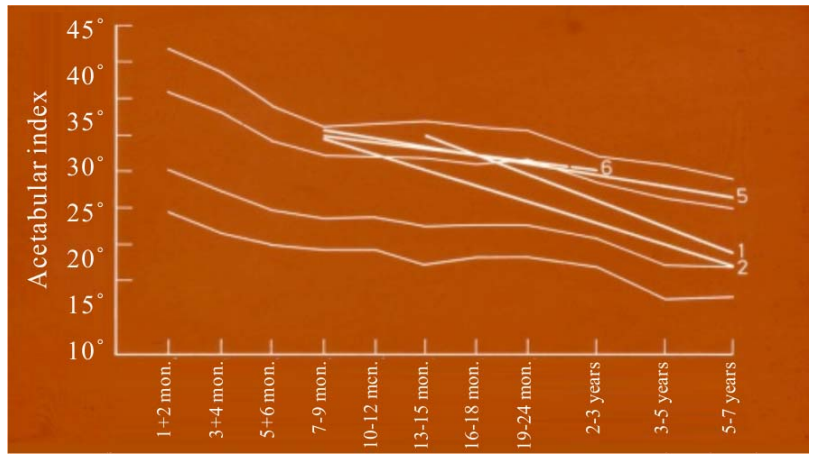

Figure 1. Normal acetabular index.

\subsection{Femoral Neck Anteversion Angle}

The angle of torsion is called anteversion, anterotation, or anterior twist; similarly, if it points backward (posterior to the transcondylar plane), it is called retroversion, retrotorsion, or posterior twist [17].

There are many imaging methods described and used for measuring femoral anteversion, we agree Ruby's opinion favor the use of the Ryder-Crane technique [18] Biplanar method (Ryder-Crane) [18]: with this technique, all roentgenograms are made with the patient supine. The $\mathrm{X}$-ray tube is positioned directly over the hip. One roentgenogram is made with the limb in neutral position (extended) and a second with the hips and knees flexed to 90 degrees and with the thighs abducted to 30 degrees, the position being maintained by a specially constructed box (cf. Figure 2). Lines representing the axis of the neck and the shaft of the femur are drawn of the first roentgenogram (cf. Figure 3). This is the apparent angle of torsion. The true torsion is determined by reference to a standard table of angles de rived from trigonometric considerations.

\subsection{Shaft-Neck Angle}

Using the AP view of the hip, angle formed by axis of femoral shaft and line drawn along axis of femoral neck passing through center of head of femur (cf. Figure 4). Normal mean angle of femoral neck-shaft according to age is an according to Dobbs and Morcuende [20] (cf. Figure 5).

\subsection{Acetabular Anteversion Angle}

AAV was analyzed in the axial sections placed parallel to the pelvic obliquity showing both the triradiate cartilages. AAV was expressed as the angle between a line perpendicular to the trans-triradiate line and a line drawn across the margins of the acetabulum, from its posterior to anterior edge, with figure of MRI evaluation of acetabular anteversion (cf. Figure 6) [21], 30 to 40 degrees is the normal range for the McKibbin instability index [22,23].

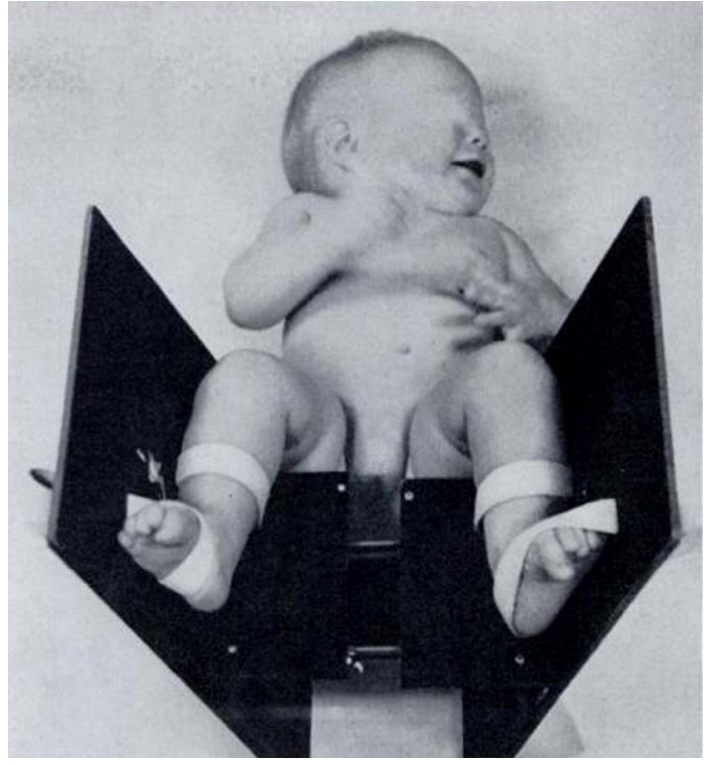

Figure 2. The limb in neutral position (extended) and a second with the hips and knees flexed to 90 degrees and with the thighs abducted to $\mathbf{3 0}$ degrees, the position being maintained by a specially constructed box.

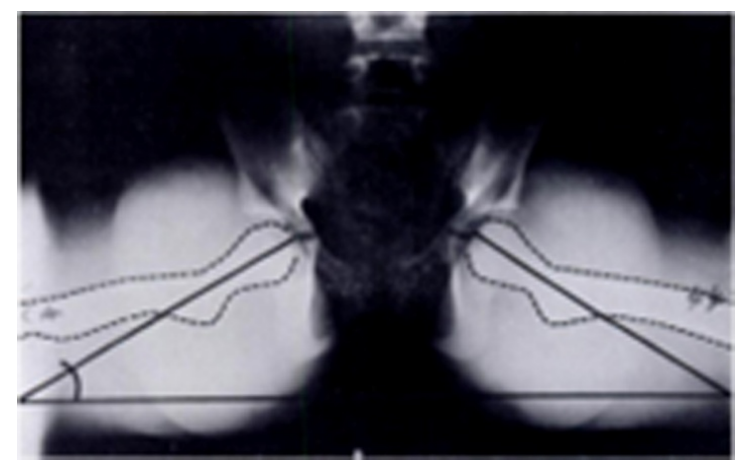

Figure 3. Lines representing the axis of the neck and the shaft of the femur are drawn of the first roentgenogram.

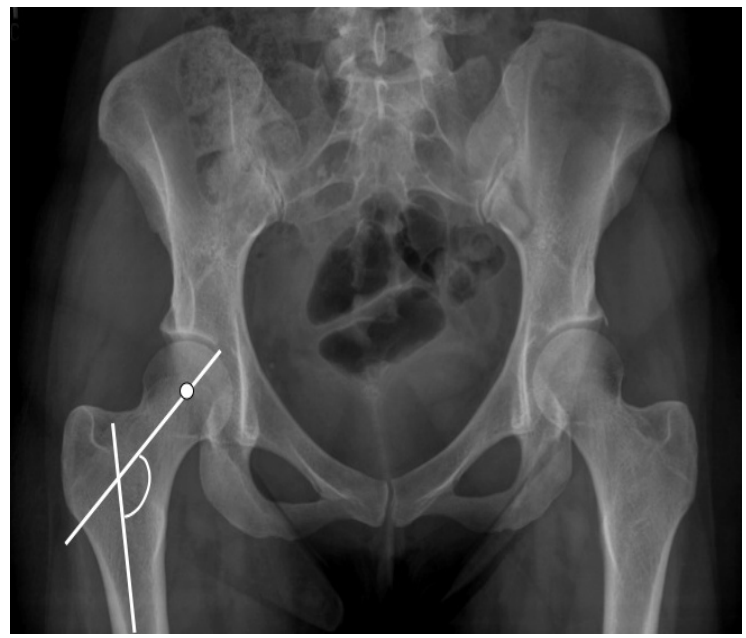

Figure 4. Shaft-neck angle. 


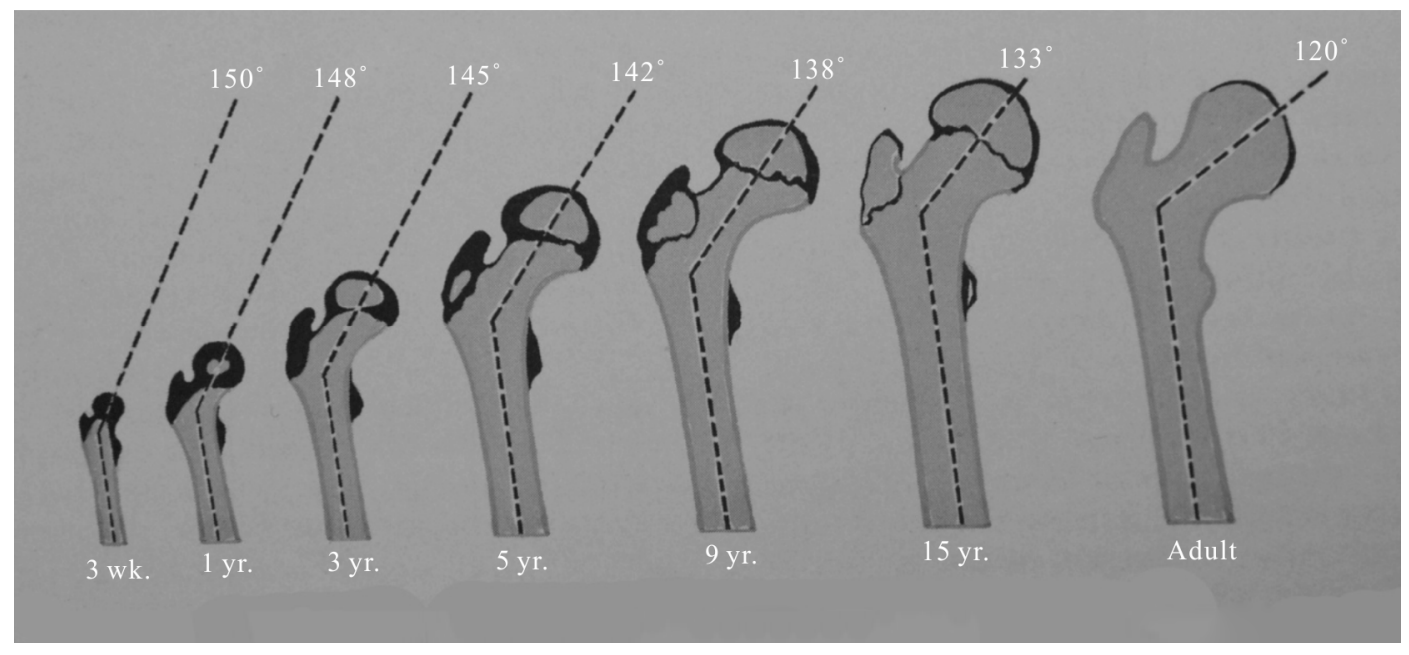

Figure 5. Normal mean angle of femoral neck-shaft according to age [20].

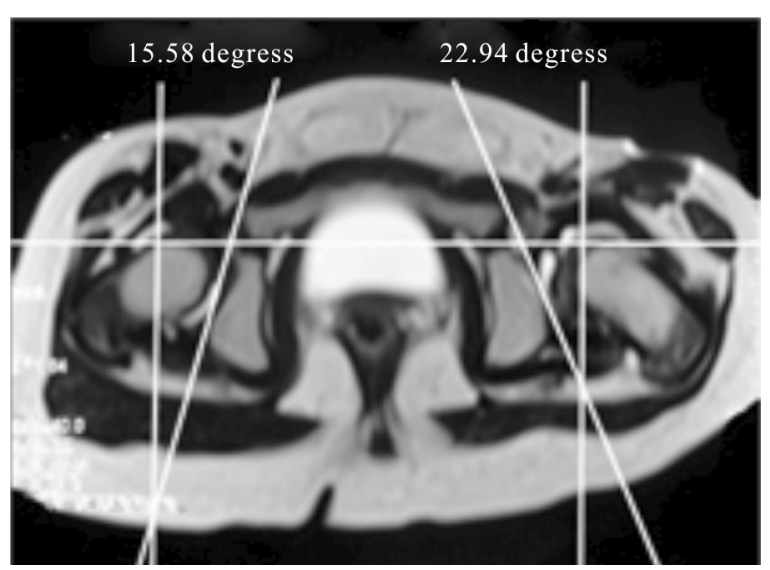

Figure 6. Acetabular anteversion.

We elected not to use the central-edge angle of Weiberg (CE angle), as the femoral heads in the majority of hips were partially ossified.

Assessment of avascular necrosis (AVN) of the femoral head was performed according to Kalamchi and MacEwen's classification [24].

History of previous treatment of the studied cases (referred cases from other medical centers) included history of the application of Pavlik harness in 12 hips (11.3\%), during the first year of life, which eventually failed, preoperative over-head traction (Brayant's traction position) using adhesive skin traction kits in 8 hips (7.5\%), whereas skeletal traction was used for two hips in a bilateral case (3.8\%) from the distal femur. All those cases referred, they have been operated in this study.

\section{Surgical Technique}

\subsection{Anterior Approach}

The patient supine a pad is placed under the affected hip so that the posterior aspect of the ilium can be exposed, when necessary, and also to facilitate anterior dislocation of the hip. The leg is draped so the hip and leg can be manipulated during the approach.

The skin incision begins at 1 centimetre below anterior superior iliac spine, the incision is extended 4 centimetres along inguinal crease (cf. Figure 7).

The superficial and deep fascia over the sartorius muscle is divided, medial to the iliopsoas muscle muscle. The Surgery exposure hip lateral femoral cutaneous nerve that penetrates the deep fascia just below the anterior superior iliac spine is identified and retracted laterally along with the sartorius muscle. The iliopsoas is also separated from the capsule by blunt dissection and the tenotomy of the psoas tendon from the lesser trochanter. The tendinous origin of the rectus femoris is separated from anterior inferior iliac spine and it is released. Most of the anterior aspect of the hip joint is then exposed.

\subsection{Open Reduction}

A "T"-shaped capsulotomy is performed with the stem of the $\mathrm{T}$ horizontal rather than in line with the neck. The capsule is then opened one centimeter from the acetabular rim, and a perpendicular cut is made extending to the base of the neck in the anterosuperior part of the capsule. Care is taken to extend the capsulotomy as medial as possible. If the lymbus is hypertrophic and released, the ligamentum teres is identified, transected, and followed down to the true acetabulum. The transverse acetabular ligament is transected and the acetabulum cleared of pulvinar. The glenoid labrum is usually found to be rolled over the rim of the acetabulum along its posterior and superior borders, and is incised in order to allow easy reduction of the femoral head into the acetabulum. More important, the completeness of the removal of obstacles 


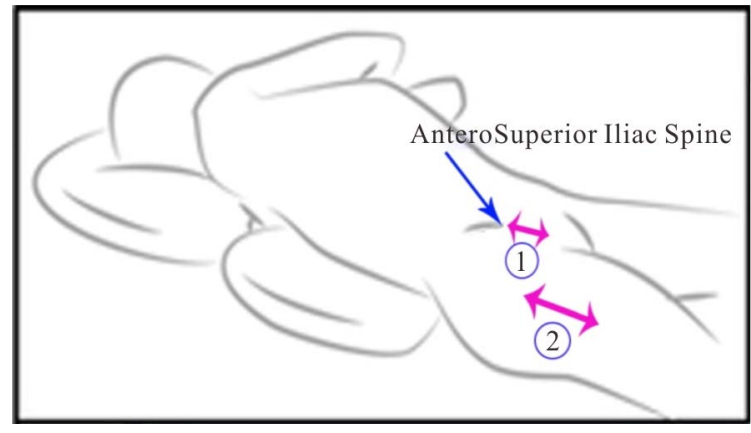

Figure 7. Skin incision. (1) Skin incision to acetabular hip; (2) Lateral approach to proximal femur.

to reduction affects the outcome.

\subsection{Femoral Shortening}

Femoral shortening should be utilized whenever hip reduction is difficult or when it appears that undue force is being produced by reduction of the hip.

Through a separate lateral approach (cf. Figure 7), the proximal end of the femur was exposed subperiosteally and a transverse osteotomy was made in the subtrochanteric region. The two femoral fragments were allowed to overlap, and reduction was obtained quite easily. A segment of femur that was 1 to 1.5 centimeters long, sufficient to relieve the muscular tension across the hip joint, was then removed. If, at the time of the trial reduction of the hip, internal rotation of the femur seemed to contribute to stability of the joint, derotation was achieved by externally rotating the distal femoral fragment in relation to the proximal fragment before applying the plate. We believe that it is important to avoid excessive derotation of the femur, especially if an acetabular procedure is anticipated, as posterior instability may result. At the time of the initial reduction, if coverage of the femoral head is poor, or if the acetabulum is clearly maldirected, then we would plan to perform Modified Salter Inniminate Osteotomy (MSIO). The osteotomy is then fixed rigidly with a pediatric blade-plate or a 3.5 dynamic-compression plate. The hip is reduced concentrically, and the adequacy of the acetabular coverage is assessed with the limb in the weight-bearing position. If coverage is inadequate, a pelvic osteotomy is performed.

\subsection{Modified Salter Innominate Osteotomy}

In all hips, the position of maximum stability was assessed at the time of open reduction. The hips which required flexion with abduction for stability and/or had an acetabular angle above $35^{\circ}$ on the pre-operative radiograph, were judged to require an innominate osteotomy.
Expose inner table of the ilium, did not expose outer table of the ilium. A drill is used to outline iliac osteotomy. The first line, transversal line at just above anterior inferior iliac spine $5 \mathrm{~mm}$; the second line, oblique to create angle $135^{\circ}$ with the line first line and go down and $7 \mathrm{~mm}$ length; the thirst line, to go internal obliquely to create angle $60^{\circ}$ with the second line and to the transversal level of the first line; the fourth line, connective thirst line and go down and $10 \mathrm{~mm}$ length and to the transversal level of the first line; the fifth line, perpendicular to the fourth line, to go internal iliac and $5 \mathrm{~mm}$ length (cf. Figures 8(a) and 8(b)). After outlining the iliac osteotomy is created by multiple drill-holes, a small sharp osteotome is used to complete the cuts by connecting those drill-holes.

\subsection{The Next Step, Place Mechanical Stretch Ilium}

To assemble mechanical stretch and bigining to stretch ilium, distal and proximal segment of ilium with $15 \mathrm{~mm}$ is needed. Next, using small curette to remove cancellous in both side proximal and distal segment of ilium to create a slot receiving fibula allograft (cf. Figure 9).

The Fibular Allograft is placed between the two fragments and maintains the displacement, so that Fibular grafting lateral displacement $2 \mathrm{~mm}$ is needed. To remove the mechanical stertch, and fibular allograft is compressed between proximal segment and distal segment of the ilium (cf. Figures 10(a) and (b)). To measure distance superior and inferior border of iliac segments with $11-13 \mathrm{~mm}$ is available, equal distance from anterior superior iliac spine to anterior inferior iliac spine according to Salter's technique [4].

The osteotomy should be very stable once the two segments are engaged. The rotation of the distal segment occurs through the pubic symphysis, as in the Salter osteotomy, and is pulled in exactly the same way, so that anterior and lateral acetabular coverage occurs simultaneously, as described by Salter and by Salter and Dubos $[4,25]$.

The osteotomy is held open with a wedge of bone graft, whose base is the length from the anterior superior to anterior inferior iliac spine, which reliably improves anterior and lateral coverage by 25 degrees and 15 degrees, respectively [15].

\subsection{Prepare Fibular Allografting Segment}

The fibula allografts that were used in this treatment protocol were imported from bone banks that adhere to the standards of Asia Association Surgery Tissue Bank. These grafts are of a processed type (freeze-dried) which have been proven to be safe [26]. 


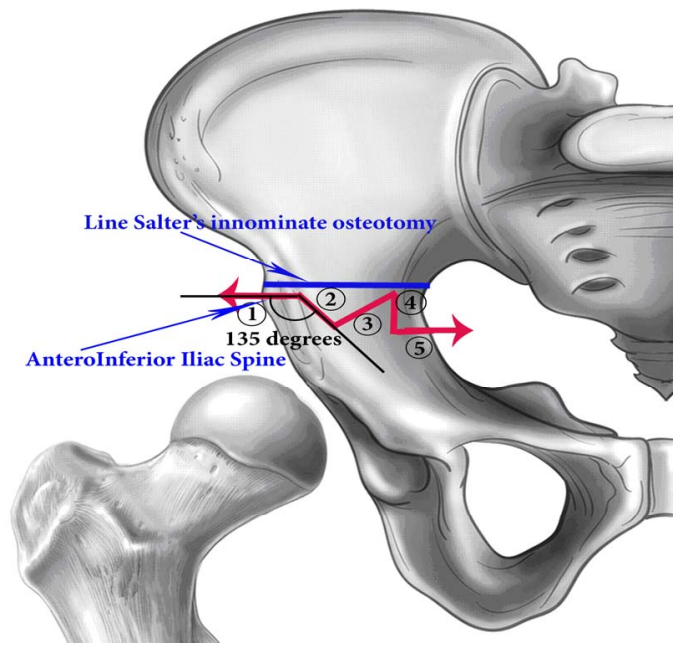

(a)

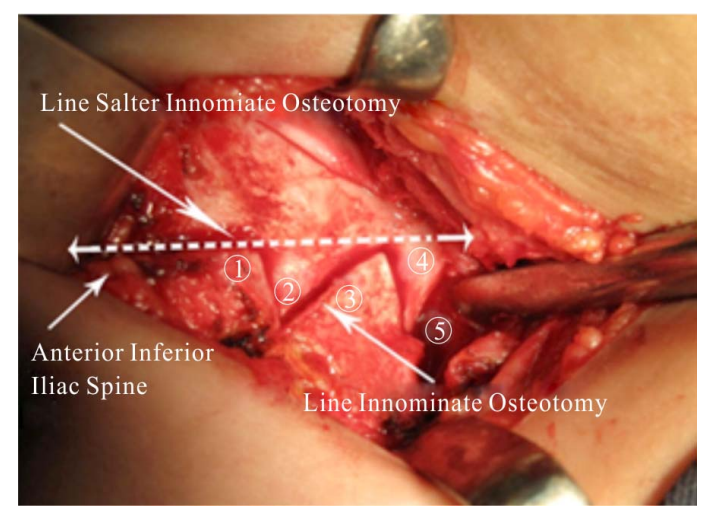

(b)

Figure 8. (a) Outlining the iliac osteotomy; (b) Line osteotomy of the ilium.

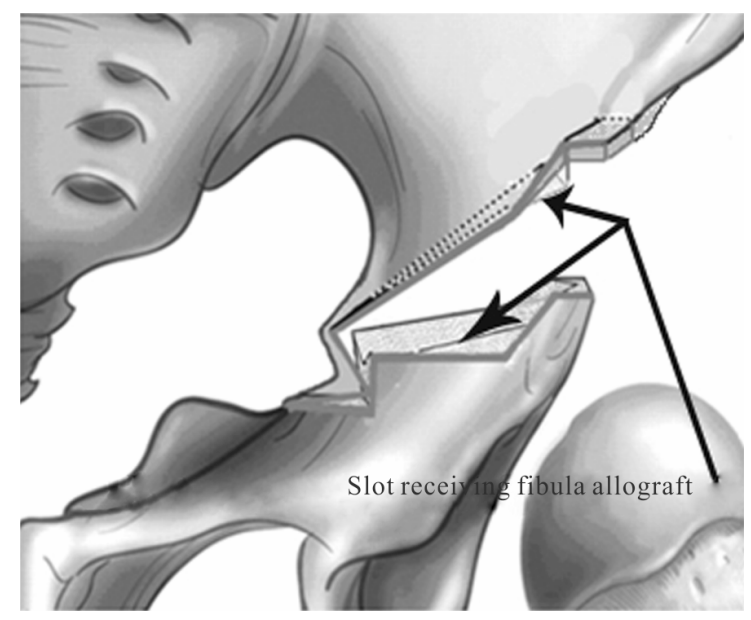

Figure 9. Slot receiving fibula allograft.

Fibular allograft is prepared after stretch ilium. Preforming Fibular allograft osteotomy to create wedge of bone graft (cf. Figures 11(a) and (b)). The length D add 2 to
$3 \mathrm{~mm}$ inferior iliac spines [27]. The length of side B is measured intraoperation and add 2 to $3 \mathrm{~mm}$ (cf. Figures 11(a) and (b))).

If the hip was still unstable, these Kirschner wires were used to maintain concentric reduction. The wire was passed through the greater trochanter and into the ilium above the capsule after capsulorrhaphy and was retained seven days.

After the capsulorrhaphy is completed, the reduction can be checked by immediate radiograph. The capsular repair should hold the femoral head securely in the acetabulum. The wound is closed.

\subsection{Postoperative Care}

The spica cast was applied immediately after surgery, hip in 30 degrees of flexion, 30 degrees of abduction, and 20 degrees of internal rotation.

Three months after surgery, the entire cast is removed, and Patients then wear the abduction orthosis full-time except for bathing (during which time the hips are kept in abduction). At about 6 months after surgery, the patient

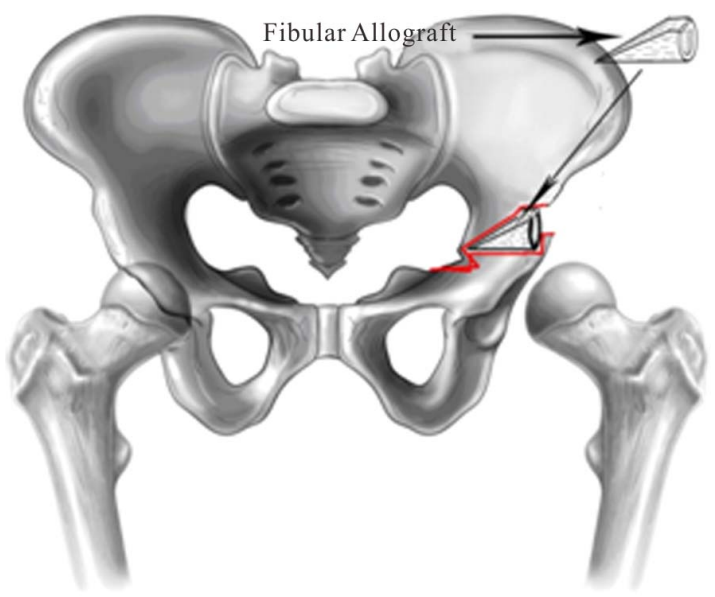

(a)

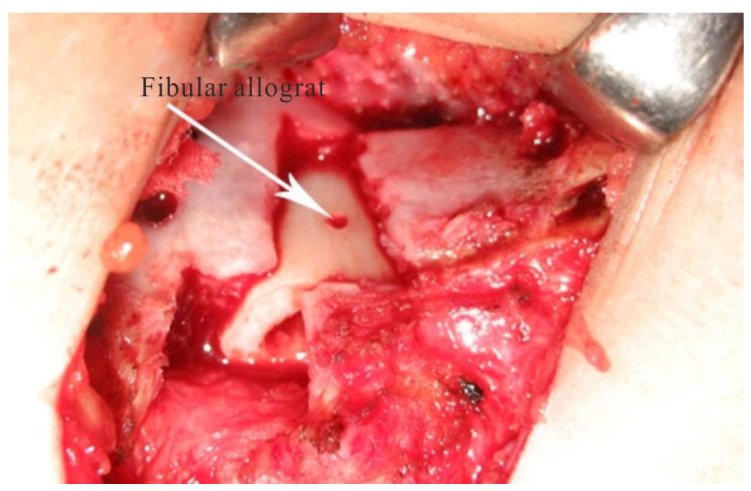

(b)

Figure 10. (a) (b) Fibular allograft is placed between the two iliac fragments. 


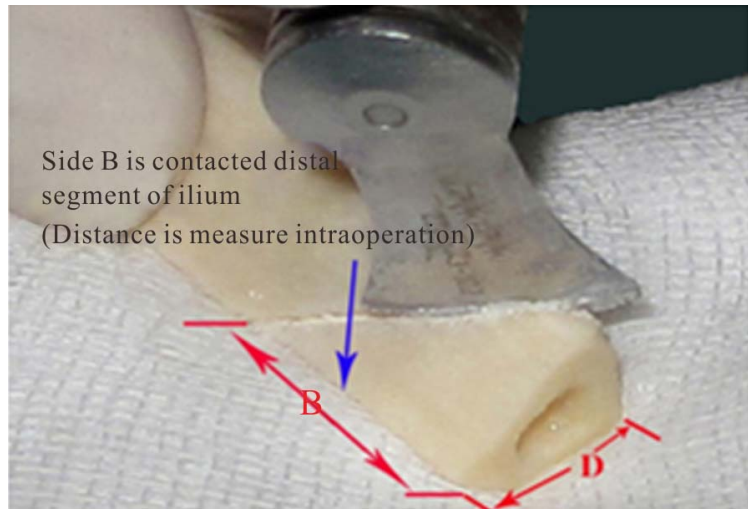

(a)

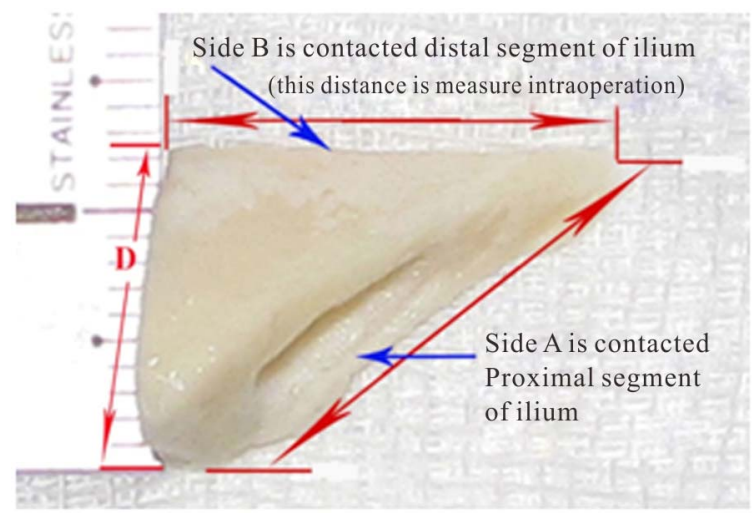

(b)

Figure 11. (a) Osteotomy of fibular allograft; (b) Wedge of fibular allograft.

is gradually weaned from the brace to wear haft spica cast it only at night and nap time until acetabular development is normal. The haft spica cast (cf. Figure 12) is usually worn for an average of 12 to 24 months after surgery. Weight bearing was not allowed until radiographic evidence of healing of the osteotomy site was obtained.

In bilateral cases, the other hip was operated upon after 3 months from the first side, and then the hip spica cast was applied for immobilization of both hips.

The allograft was considered to have been stable if the correction of the dysplastic acetabulum was maintained during the 2-year post-operative period and non extrusion of the graft had occurred from the osteotomy site. Fibular allograft incorporation into the ilium was considered to have taken place if complete union at the osteotomy site had occurred and confluence of the graft to the ilium was evident on the $\mathrm{X}$-rays.

\subsection{Evaluating Result}

The patients were scheduled to return to the outpatient clinic at three months intervals during the first day post-operatively and at 3 months, 6 months, 1 year, and

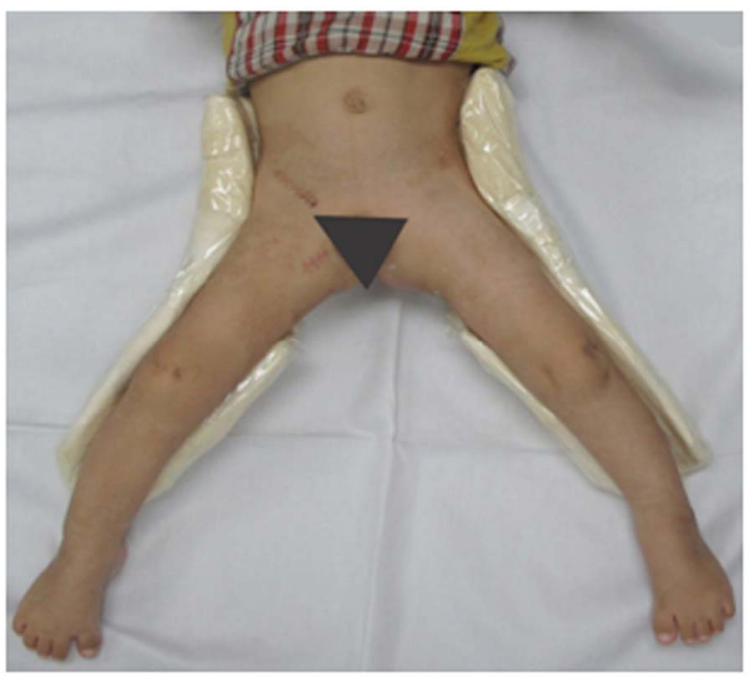

Figure 12. Patient is weared haft spica cast.

2 years after surgery and then at yearly intervals. The patients were evaluated clinically during each visit as to the range of motion of the affected hip, the quality of gait, Trendelenburg test, and the presence of any pain. Radiographs of each hip were made to assess the quality of reduction, the acetabular index, and the presence or absence of avascular necrosis. Each patient's preoperative radiographs were evaluated to determine the affected hip's acetabular index and station.

Barrett's modification of McKay's criteria [28] was used for the clinical assessment of postoperative results: Excelent result: Stable, painless hip, no limp, negative Trendelenburg sign, full range of motion. Good result: Stable, painless hip, slight limp, slight degree in range of motion. Fair result: Stable, painless hip, limp, positive Trendelenburg sign, and limited range of motion, or a combination of these. Poor result: Unstable or painful hip, or both; positive Trendelenburg sign. All operations were performed by a single surgeon, which increases the homogeneity of the patient group.

\section{Results}

Between January 2004 and December 2008, 106 surgeries were performed in 95 patients. Sixty-nine (72.6\%) of the patients were girls and twenty-six (27.4\%) were boys. Thirteen patients (13.7\%) were between twelve and eighteen months old at the time of the operation, the remaining eighty-two (86.3\%) patients being between eighteen and thirty-six months old, with the mean age of 22.6 month at the time of surgery. There were eleven (11.6\%) patients had bilateral dislocation. Eighty-four (88.4\%) patients were affected unilaterally. The right hip was involved in seventeen (17.9\%) and the left hip in sixty-seven $(70.5 \%)$ cases. 
Three of the patients with a unilateral dislocation had a history of dysplasia in the contralateral hip which had been successfully treated by nonoperative means before they were one year old.

Tönnis system Typ 3 in 34 hip (32.1\%), and Type 4 in 72 hip (67.9\%).

The anterior approach was used to expose inner table of the ilium and Modified Salter Innominate Osteotomy (MSIO) with fibular allografting in all cases.

Femoral shortening was performed in 10 hips (9.4\%), all of them more than 24 months at time of the operation. The Kirschner wires (KW) did not use to fix the fibular allograft at the pelvic osteotomy site.

All of the fibulat allografts were completely incorporated mean 14 weeks (range, 12 weeks - 17 weeks), postsurgery (cf. Figures 13(a)-(c)) without graft was related infections.

The average operative time was 95 min (range 80 $105 \mathrm{~min}$ ). Radiographs were made preoperatively, and immediately postoperatively.

The blood loss from this procedure is acceptable. Postoperative blood transfusion was no required.

There were 9 hips of them (8.5\%) with acetabular index more than $50^{\circ}$. The preoperative Acetabular Indices, mean was $42.957^{\circ}$, ranged from $36.17^{\circ}$ to $51.56^{\circ}$ ( $\mathrm{SD}=$ 4.4046). Compared AI Preoperation and AI Immediate postoperation with Pvaluate is 0.0000001 ; AI Immediate postoperation and AI Postoperative 3 months with Pvaluate is 0.0000001; AI Postoperative 3 months and AI Postoperative 6 months with Pvaluate is 0.0000001; AI Postoperative 6 months and AI Postoperative 12 months with Pvaluate is 0.0000001; AI Postoperative12 months and AI Postoperative 24 months with Pvaluate is 0.0000001; AI Postoperative 24 months and AI latest follow-up with Pvaluate is 0.202263 .

Femoral Necl angle: Average 27.726 $(\mathrm{SD}=12.153)$

Shaft-Neck angle: Average $149.649^{\circ}(\mathrm{SD}=5.815)$

Acetabular Anteversion: Average: $21.233^{\circ}$ (SD = 5.264)

\subsection{Open Reduction}

Capsular Hip was opened and there were three components had payed attention to release were ligamentum teres, transverse acetabular ligament, pulvinar, and labrum:

Ligamentum teres: 106 (100\%)

Transverse acetabular ligament: 86 (81.1\%)

Labrum: 95 (98.62\%)

Pulvinar: 106 (100\%)

Two redislocations occurred after a successful open reduction, one during the first three months of mobilization, and one after three months. Three subluxations occurred after a successful open reduction, one during the

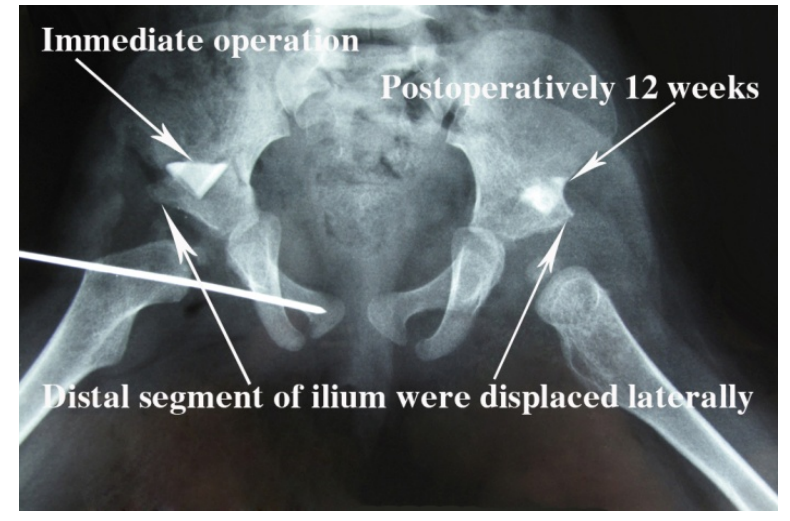

(a)

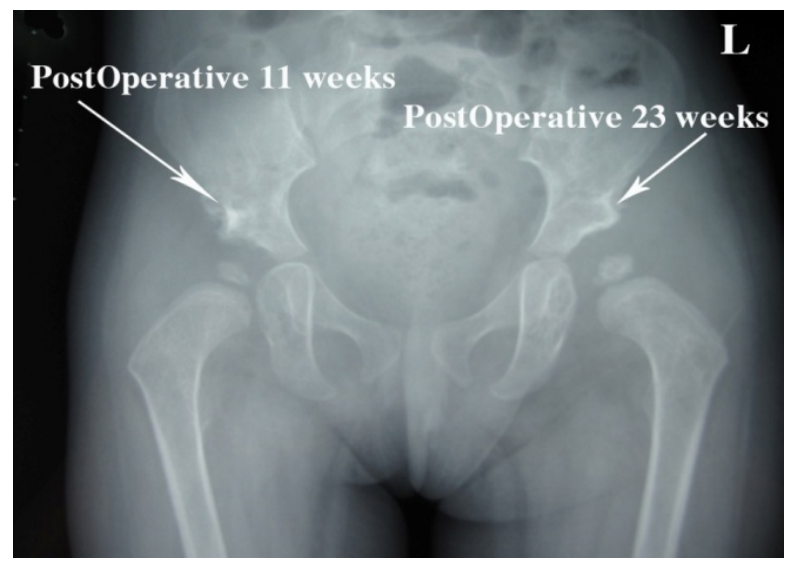

(b)

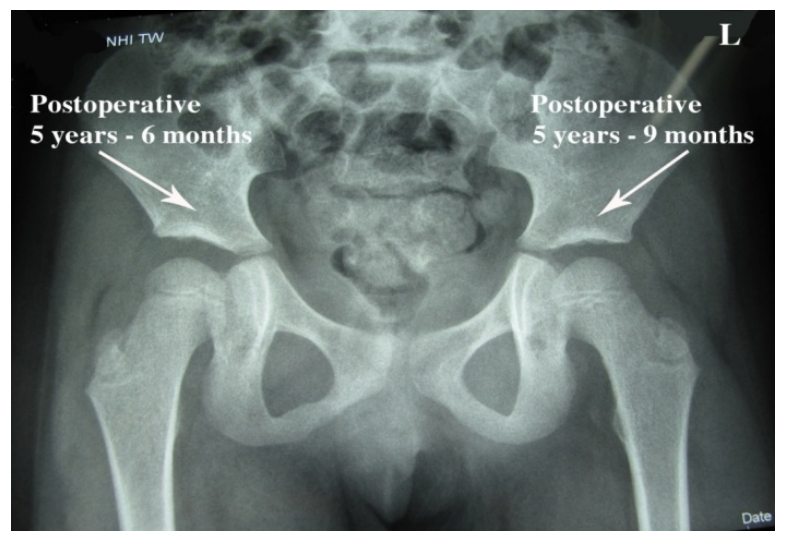

(c)

Figure 13. Potoerativly. (a) Left hip, postoperatively 12 weeks; right hip, imeediate operation; (b) Left hip, postoperatively 23 weeks; right hip, postoperatively 11 weeks; (c) Left hip, postoperatively 5 years - 9 months, right hip, postoperatively 5 years - 6 months.

period of immobilization, one during the first three months of mobilization, and one after three months (cf. Figures 14(a) and (b)). The median time to the recognition of failure was four months. However, five hips had angles were measured with normal limits at latest follow-up. 


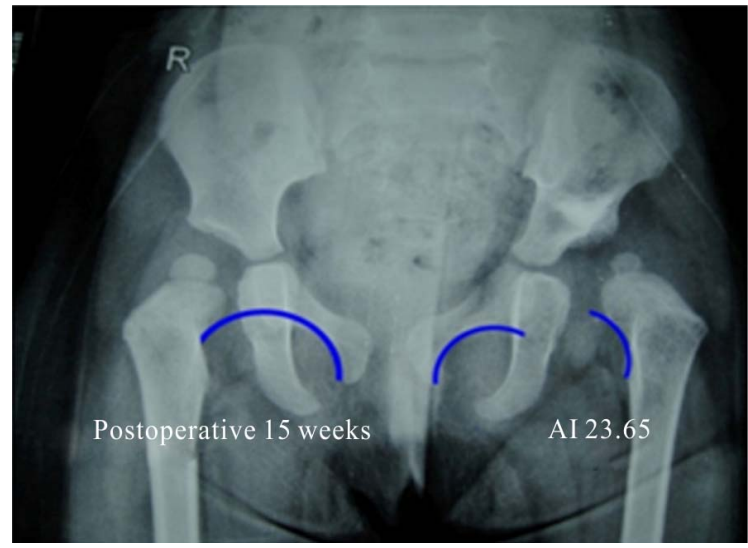

(a)

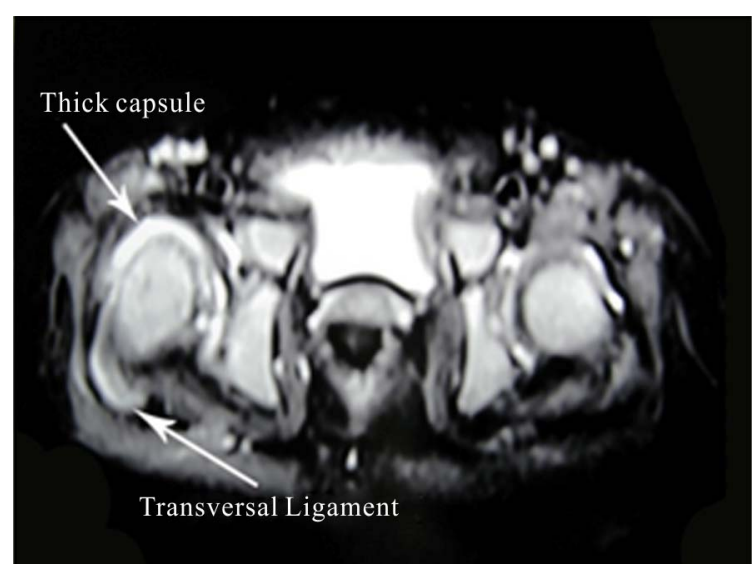

(b)

Figure 14. Postoperatively 15 weeks, left hip with subluxation: (a) Roentgenography shown acetabular index with normal limits; Broken Shenton line; (b) MRI shown thick capsule and hypertrophic transverse ligamentum.

AVN: In the Type III: 2, Type IV: 1 . Those 5 of 106 hips (4.7\%) cases had a relatively large head of the femur (coxa magna) at the latest follow-up roentgen, 3 cas in Type III and 2 cas in Type IV (cf. Figure 15).

The presence of AVN and the type according to Kalamchi and MacEwen [24] was observed to be present in 4 of 106 hips (3.8\%). One hip (0.9\%) developed type 1 AVN, and 3 hips (2.8\%) type 2 AVN, and no type 3 and 4 AVN was seen (cf. Figure 16).

At the time of the latest follow-up, 99 of the 106 patients (93.4\%) had good or excellent hip function according to McKay's classification. Hip function was fair and poor in 7 patients because of limited motion, mainly involving internal/external rotation of the hip. Femoral head deformity was observed in the 5 hips. In terms of the radiological results, 74 hips were classified as Severin's class I; 23, class II; and 9, class III. Good or excellent radiographic results were noted for 97 of the 106 hips (91.5\%).
Final results: Excellent 70 (66.0\%), Good 29 (27.4\%), Fair 2 (1.9\%), Poor 5 (4.7\%).

\subsection{Other Complications}

Our patients without wound infection, nerve injury, femoral fracture, stiffness, and residual dysplasia.

\section{Discussion}

Bone grafts are widely used in paediatric orthopaedic surgery. Autogenous bone grafts remain the "gold standard" in reconstructive surgery because of their osteoinductive, osteoconductive, and non-immunogenic properties. The iliac crest is the most common donor site because of easy access and procurement, and availability of large quantities of both cortical and cancellous bone.

Trevor DLJ and Fixen JA 1975 [30] performing acetabuloplasty in the treatment of Congenital Dislocation of the Hip with use of bone bank rib grafts. Kessler et al. 2001 [31] use of allografts in Pemberton osteotomies with patellar allograft wedges, which allows good correction of acetabular dysplasia with immediate graft stability. Grudziak and Ward 2001 [32] with the height of

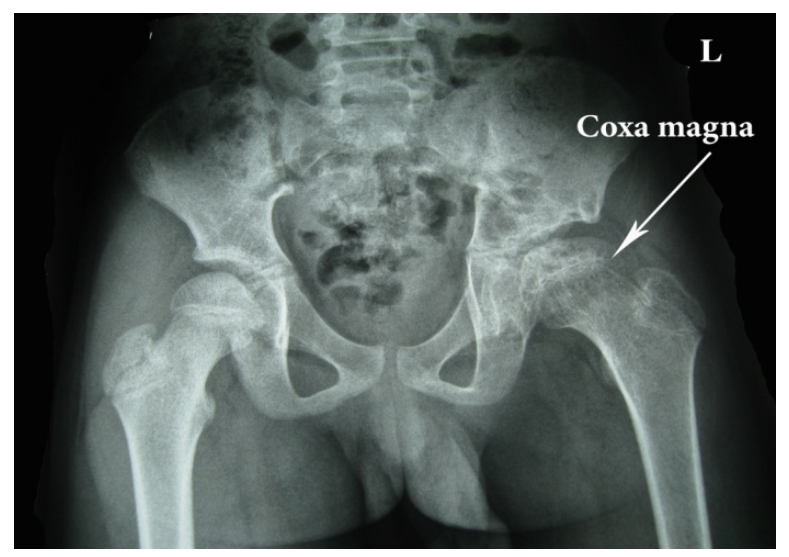

Figure 15. Left hip with coxa magna.

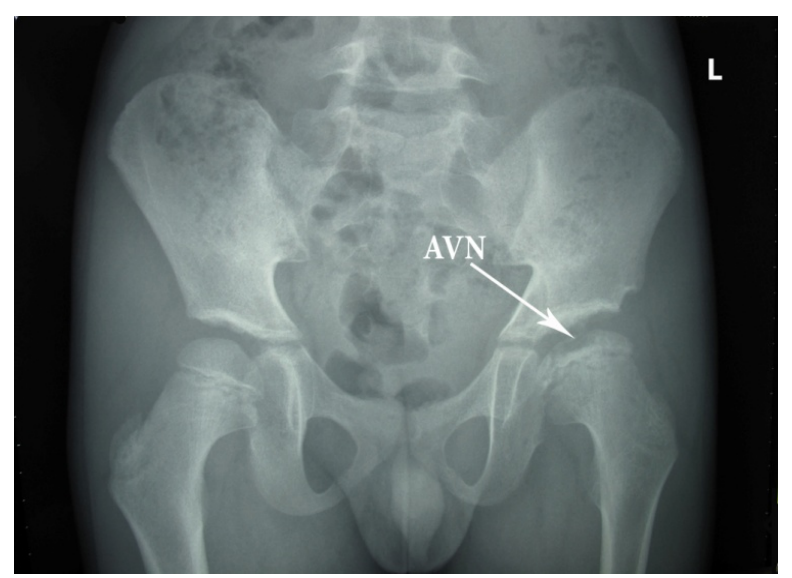

Figure 16. Left head femur with AVN. 
the graft can be increased by utilizing freeze-dried fibular allograft cut into trapezoidal sections in Dega osteotomy. Wade 2010 [33], used iliac crest allograft interposition for pericapsular acetabuloplasty in developmental dislocation of the hip. In this study, we used single fibular allograft only.

In congenital dislocation of the hip with anteversion, many authors, such as Werndorff, in 1912 [34], Hihbs, in 1915 [35], Krida, Colonna and Carr, in 1936 [36], McCarroll and Crego, in 1939 [37], and Massie and Howorth, in 1951 [38], advocated a rotation osteotomy either in the supracondylar or subtrochanteric area of the femur to correct the anteversion. Dunn, Notley in 1952 [39] sad that in fact clinical examination of the hip is sometimes more accurate. It has been said that the only certain way of determining the angle of anteversion is by operative exposure of the hip [39].

Massie and Howorth [38], as well as Durham [40], recommended that a femur with an anteversion of more than +45 degrees should be corrected by osteotomy; Sankar et al. in 2011 [41] derotation of the femur is planned if there is more than 50 degrees of femoral anteversion. while Warndorf [34] only did a correctional osteotomy if it was +60 degrees or over, and Berkeley et al. in 1984 [11] with femoral anteversion in excess of 60 degrees as determined at the time of open reduction is considered an indication for derotational osteotomy. This was done either before or after reduction. Hibbs, in 1915 [35], also advocated the osteotomy, often times before reduction; however, Farrell, von Lackum, and Smith, in 1926 [42], from Hibbs Clinic, wrote that ordinarily osteotomy should not be done until after the hip had been reduced. Others, such as Lorenz [43], Bradford [44], Soutter [45], and Compere and Schnute [46], were of the opinion that an osteotomy is not necessary for a good result and that the anteversion will usually correct itself. Lorenz, in 1905 [43], went so far as to say that operative correction of the anteversion may lead to a posterior subluxation. Bradford, in 1923 [44] wrote that, if the reduction has been complete and stable, locomotion and joint function becomes normal despite the femoral twist which tends to correct itself after reduction. Soutter and Lovett, in 1924 [45], stated that, in their experience, cases of congenital dislocation with extreme torsion have improved markedly after two or three years of weight- bearing. Fairbank, in 1930 [2], stated that, if the hip is reduced before the fourth year, it is very rare to have to do a rotation osteotomy in order to correct the anteversion. We advocated those authors's opinion so did not derotation osteotomy of the femur to correct the anteversion.

We agree with Kumar et al.'s [47] opinion that the femoral shortening might prolong the operating time, increase blood loss, or increase the incidence of het- erotopic bone formation.

The first English-language description of an incomplete transiliac osteotomy for the treatment of acetabular dysplasia secondary to congenital dysplasia of the hip appears to be that written by Albee in 1915 [48]. Albee described a semicircular osteotomy of the lateral part of the acetabular rim that was directed obliquely from lateral to medial just cephalad to the attachment of the hip capsule into the ilium.

The goal of treatment is to obtain and maintain a stable, concentrically reduced hip joint at as early an age as possible while minimizing complications [49]. In this study, the comprehensive single-stage approach, which includes open reduction, capsulorraphy, and MSIO was performed in all the cases included. The procedure in question reduces the hip and recreates as normal anatomy as possible to allow for and to stimulate a rapid hip development. Weinstein et al. [50] also concluded that combining primary open reduction, femoral shortening, capsulorraphy, and acetabuloplasty in a single operation allows predictable treatment of the congenital dislocation of the hip in older children without the time and expense of preliminary traction.

The fibular allograft is contoured to conform to the configuration of the osteotomy site. This like triangular configuration of the contoured allograft and the substantial surface area there of due to its width contributes to the stability of the graft, which is further augmented by the inherent recoil plasticity of the acetabulum roof. There are two bar osseous and two slots in proximal and distal segment of the ilium, this stability is evident intra-operatively by the graft not being able to be translated or rotated or sliped. This exceptional graft stability eliminates the need for routine internal fixation of the osteotomy. Graft extrusion or displacement was not encountered in our series.

The fibular allografts were all incorporated into the ilium and the osteotomies were fully healed by 17 weeks post-operation, with the average incorporation time being 14 weeks. This 17 weeks time frame was deemed to be sufficient to effectively assess the biologic response of the allograft within the ilium.

This surgical protocol yielded concentrically reduced and stable hips in $93.7 \%$ of hips treated. The average correction of the dysplastic acetabulae was $18.67^{\circ}$. The AI was maintained in the post-operative period and improved spontaneously over the ensuing 6-month period to a mean of $21.07^{\circ}, 19.45^{\circ}$ and in the post-operative period 2 years, and 19.15 at latest follow up. We ascribe the maintenance of the AI to the structural integrity of the allograft and the improvement of the AI to the concentric reduction and continued stability of the relocated hip (see Tables 1 and 2). 
Table 1. Normal values for femoral neck anteversion [19].

\begin{tabular}{|c|c|c|c|}
\hline \multirow{2}{*}{ Age (years) } & \multicolumn{3}{|c|}{ Anteversion (degrees) } \\
\hline & Dunlap et al. [4] Shands and Steele & Ryder and Crane [K] & Average \\
\hline & 39 & 41 & 40 \\
\hline 1 & 35 & 37 & 36 \\
\hline 2 & 31 & 37 & 34 \\
\hline 3 & 20 & 35 & 32 \\
\hline 4 & 29 & 31 & 30 \\
\hline 5 & 28 & 26 & 27 \\
\hline 6 & 27 & 26 & 26 \\
\hline 7 & 26 & 25 & 25 \\
\hline 8 & 25 & 24 & 24 \\
\hline 9 & 25 & 22 & 23 \\
\hline 10 & 24 & & \\
\hline 11 & 24 & & \\
\hline 12 & 24 & & \\
\hline 13 & 23 & & \\
\hline 14 & 22 & & \\
\hline 15 & 18 & & \\
\hline 16 & 16 & & \\
\hline Over 16 & 15 & & \\
\hline
\end{tabular}

Table 2. Comparision of acetabular index preoperative and latest fellow-up.

\begin{tabular}{ccccccc}
\hline $\begin{array}{c}\text { Acetabular } \\
\text { Index }\end{array}$ & Preope. AI & $\begin{array}{c}\text { Immediate } \\
\text { postope. AI }\end{array}$ & $\begin{array}{c}\text { Postope. } \\
\text { AI 3 months }\end{array}$ & $\begin{array}{c}\text { Postope. } \\
\text { AI 6 months }\end{array}$ & $\begin{array}{c}\text { Postope. } \\
\text { AI 12 months }\end{array}$ & $\begin{array}{c}\text { Postope. } \\
\text { AI 24 months }\end{array}$ \\
\hline Mean & 42.957 & 25.562 & 22.915 & 21.706 & 20.546 & 19.450 \\
latest follow-up
\end{tabular}

Preope. Preoperative; Postope; Postoperative; AI. Acetabular Index.

Adam [51] recommended the use of a heterogeneous bone graft instead of the iliac crest graft in children less than 3 years of age to maintain the pelvic osteotomy.

None of our patients had any other above-mentioned complications and we believe that this favourable outcome could be attributed to the fibular bone graft being too strong to be crushed easily, as sometimes occurs with a cancellous bone graft.

Kalamchi [31] described a modification where the distal fragment fits into a notch in the ilium, which increases the stability of the osteotomy. Marafioti and Westin [52] described a modification in which a greenstick fracture is produced in the remaining portion of the ischium. We performed innominate osteotomy (see Figure 8) to create osteotomy line 4 and 5 so to prevent posterior displacement of the distal fragment too.

In the classic Salter osteotomy, the distal fragment is inclined downwards, which makes the graft prone to displacement. The technique which we describe follows the same philosophy, but uses an oblique osteotomy. Fol- lowing the redirection of the osteotomy, the distal iliac fragment becomes horizontal, which produces a more stable situation for the bone wedge. We suggest this is the main factor that increases stability. However, we recognise that this is speculative, and further biomechanical studies should be undertaken to test the stability of the modified osteotomy. The change in the direction of the osteotomy does not compromise the redirection potential. Radiological evaluation demonstrated that the modified pinless Salter osteotomy produced similar results to the original osteotomy. The acetabular index was restored to within normal limits in the immediate post-operative period and continued to improve thereafter. Lin et al. [53] reported a mean of $13^{\circ}$ of correction, whereas Bohm and Brzuske [54] reported a mean of $11.9^{\circ}$ of correction with a Salter osteotomy. Ito et al. [55] reported a mean $16.4^{\circ}$ improvement in the acetabular index. Our result with mean correction of $16.8^{\circ}$ in this study was comparable to those reported in the literature and all hip had an acetabular index with normal limits at 
final follow-up.

The Salter osteotomy is suitable for an acetabulum with a short iliac part and an acetabular angle of up to $35^{\circ}$, whereas the Pemberton acetabuloplasty is suitable for an acetabulum with a long iliac part and an acetabular angle of up to $50^{\circ}$ [56,57]; In this study there are 9 hips > $50^{\circ}$ only.

The original SIO describes both tables of the ilium to be exposed, which increases the amount of intra-operative bleeding [54]. Our technique did not expose outer table of the ilium, so abductor muscle is not injury so negative Trendelenburg test. The blood loss from this procedure is acceptable. Post-operative blood transfusion was no required.

\subsection{Redislocrtion and Subluxation}

In congenital dislocation of the hip (CDH) failure to obtain a stable concentric reduction after open operation is uncommon, occurring in about $3 \%$ of procedures performed through an anterior approach and 5\% to $14 \%$ of medial approaches [15]. Previous reports have detailed several causes of recurrent dislocation, the problems of its management, and the medium-term results [56].

In any type of congenital dislocation, the cause of the failure of treatment can be found at one of the following times: 1) At the time of reduction; 2) During immobilization; and 3) After immobilization. Two redislocations occurred after a successful open reduction, one during the first three months of mobilization, and one after three months. Three subluxations occurred after a successful open reduction, one during the period of immobilization, one during the first three months of mobilization, and one after three months. The median time to the recognition of failure was four months in all, but one of the unilateral right redislocation, who operated bilateral hip, failure to maintain reduction could be attributed to an inadequate soft tissue release or insufficient clearance of the structures, which obstruct reduction. Our findings in these unilateral cases agree with others $[57,58]$. We suggest that technical failure namely inadequate soft tissue release is usually the cause for redislocation in unilateral dislocations. In bilateral dislocations, no obvious reason was evident, and it may be that the biological behaviour of these hips is in some way different (see Table 3).

Capsulorrhaphy failure. In three patients, there had been laxity and thinning of the anterior capsule suggesting that the primary capsulorrhaphy had ruptured. The success of the capsular repair is very important in the first few weeks after open reduction; undue tension applied either anteriorly or posteriorly may cause dehiscence or stretching. Failure to tighten the posterior capsule may lead to posterior subluxation of the head, espe- cially if a Salter osteotomy has been performed simultaneously. Our findings in these respects agree with those of Bos and Slooff [57] and McCluskey et al. [7].

Earlier studies have attempted to explain the reasons for redislocation of the hip after open reduction but have been limited by their small size and their uncontrolled nature. In most cases, the cause of failure has been attributed to technical shortcomings such as inadequate release of the psoas tendon, transverse acetabular ligament, or inferomedial capsule [41,59]. To our knowledge, no earlier studies have discussed radiographic predictors for failure, and none have provided controls for comparison. As such, the risk factors for failure after a technically proficient open reduction remains poorly understood.

\subsection{Complications and AVN}

In the 1960, the treatment of congenital dislocation of the hip improved markedly. Prior to this period the incidence of avascular necrosis involving the femoral head was as high as 70 percent following reduction [60]. Avascular necrosis has come to be understood as a largely iatrogenic entity and emphasis has been placed on release of soft-tissue tension by such means as traction or femoral shortening [61,62]. As a result the incidence of avascular necrosis has been reported to be as low as 5 per cent after closed treatment and zero per cent after open reduction [60,63].

Sankar and et al. [41] found the abduction in the spica cast was significantly higher in the control patients (mean 50.8 degrees) compared with those who failed open reduction (mean 38.8 degrees). Increased abduction in the spica cast is likely effective for 2 reasons. First, abduction can prevent redislocation during the casting period by directing forces more perpendicular to the mouth of the acetabulum, and second, increased abduction may improve acetabular remodeling during the period of immobilization so that the acetabulum is a better shape upon cast removal. Salter and others have warned against immobilization in excessive abduction as this increases the risk of osteonecrosis [64] but to our knowledge, the correlation between abduction and osteonecrosis has only been shown in flexed hips after closed reduction, not the relatively extended position after open reduction. Salter, himself, preferred a spica cast with the hip placed in slight flexion, approximately 45 degrees of abduction, and mild internal rotation to maintain a concentric reduction. Although the AVN rate in our control group was high (40.9\%), it is quite similar to the incidence reported in other studies using similar methods for the evaluation of osteonecrosis [65,66].

The relationship between hip abduction and blood- 
Table 3. Dislocation and subluxation.

\begin{tabular}{|c|c|c|c|c|c|c|c|c|c|}
\hline \multirow{2}{*}{$\begin{array}{l}\text { Age at } \\
\text { surgery }\end{array}$} & \multirow{2}{*}{ Sex } & \multirow{2}{*}{$\begin{array}{l}\text { Site } \\
\text { Hip }\end{array}$} & \multirow{2}{*}{$\begin{array}{c}\text { Time of } \\
\text { displacement }\end{array}$} & \multirow{2}{*}{$\begin{array}{c}\text { Type of } \\
\text { displacement }\end{array}$} & \multicolumn{4}{|c|}{ Angles were measured } & \multirow{2}{*}{ Defined cause Any obstruction } \\
\hline & & & & & AI & FNA & SNA & AAV & \\
\hline 28 months & M & B.R & 3 months & Tönnis 3 & $23.2^{\circ}$ & $33.3^{\circ}$ & $141.2^{\circ}$ & $33.3^{\circ}$ & $\begin{array}{l}\text { Released incompletely labrum and } \\
\text { transverse acetabular ligament }\end{array}$ \\
\hline 32 months & $\mathrm{F}$ & L & 3months & Tönnis 3 & $24.1^{\circ}$ & $26.1^{\circ}$ & $154.1^{\circ}$ & $22.5^{\circ}$ & $\begin{array}{l}\text { Released incompletely transverse } \\
\text { acetabular ligament }\end{array}$ \\
\hline 26 months & $\mathrm{F}$ & $\mathrm{L}$ & 3 months & Tönnis 2 & $23.6^{\circ}$ & $47.9^{\circ}$ & $152.3^{\circ}$ & $22.8^{\circ}$ & $\begin{array}{l}\text { Released incompletely transverse } \\
\text { acetabular ligament }\end{array}$ \\
\hline 24 months & $\mathrm{F}$ & $\mathrm{R}$ & 6 months & Tönnis 2 & $21.3^{\circ}$ & $41.0^{\circ}$ & $140.4^{\circ}$ & $28.5^{\circ}$ & $\begin{array}{l}\text { Released incompletely transverse } \\
\text { acetabular ligament }\end{array}$ \\
\hline 28 months & M & $\mathrm{R}$ & 6 months & Tönnis 2 & $20.6^{\circ}$ & $24.8^{\circ}$ & $134.6^{\circ}$ & $24.1^{\circ}$ & $\begin{array}{l}\text { Released incompletely transverse } \\
\text { acetabular ligament }\end{array}$ \\
\hline
\end{tabular}

B. R: bilateral hip with right hip rediclocation; AI: Acetabular index; FNA: Femoral Neck Angle; SNA: Shaft-Neck Angle; AAV: Acetabular Anteversion.

Table 4. Correlation between the final clinical outcome and the preoperative dislocation grade.

\begin{tabular}{cccccc}
\hline Tönnis & Excellent & Good & Fair & Poor & Total \\
\hline I & - & - & - & - & - \\
II & - & - & - & - & - \\
III (34 hips) & 19 & 12 & 1 & 2 & 34 \\
IV (72 hips) & 51 & 17 & 1 & 3 & 72 \\
\multirow{2}{*}{ Total } & 70 & 29 & 2 & 5 & 106 \\
& $66.0 \%$ & $27.4 \%$ & $1.9 \%$ & $4.7 \%$ & \\
\hline
\end{tabular}

Table 5. Clinical end-results of the studied cases (Modified McKay [28,29]).

\begin{tabular}{ccc}
\hline Clinical staging & Number of hips & Percentage \\
\hline Excellent & 70 & 66 \\
Good & 29 & 27.4 \\
Fair & 2 & 1.9 \\
Poor & 5 & 4.7 \\
Total & 106 & 100 \\
\hline
\end{tabular}

flow velocity in the femoral head has been established with Doppler ultrasound. In normal volunteers with their hips in neutral position, mean flow was $13 \mathrm{~cm} / \mathrm{sec}$; at 30 degrees of abduction, it was $10.3 \mathrm{~cm} / \mathrm{sec}$; and at 45 degrees, $3.8 \mathrm{~cm} / \mathrm{sec}$ [67]. Clinical studies have clearly shown the protective effect of femoral shortening on decreasing joint pressure. Some authors [30] have posited that the presence of the ossific nucleus confers a protective effect on the otherwise malleable femoral head, and may thus lead to lower rates of osteonecrosis, but this has been refuted by others [30].

Some bone allograft have used such as Iliac crest (Wade et al. 2010), Patellar (Kessler et al. 2001), Rib allograft or Iliac autograft (Trevor et al. 1975), Iliac autograft and Fibular Allograft (Grudziak et al. 2001). We done innominate osteotomy, only material interposition was fibular allograft, did not internal fix, graft was not resorption. There were none complications in this study.

All of the fibulat allografts were completely incorpo- rated mean 14 weeks (range, 12 weeks - 17 weeks)

\section{Conclusions}

Innominate osteotomy combined Fibular allograft was assisted by mechanical stretch and graft was not displaced by both side proximal and distal segment of ilium with a slot receiving fibular allograft and two bar osseous. This operation was of good safety and efficacy.

Fibular allograft was of strength and graft was not resorption, more stable and structurally sound interposition material which could be contoured to the shape of the osteotomy site.

All fibular allografts were full incorporated at 17 weeks post-operation, with the average incorporation time being 14 weeks.

Acetabular index was improved preoperation was $42.95^{\circ}$, and latest follow-up $19.15^{\circ}$, concentrical acetabulum $93.7 \%$. There were five $(4.7 \%)$ redislocation and subluxation, three AVN (2.8\%) and five (4.7\%) coxa magna. Final results: Excellent 70 (66.0\%), Good 29 (27.4\%), Fair 2 (1.9\%), Poor 5 (4.7\%) (see Tables 4-6).

\section{Acknowledgements}

I would like to thank Professor. Joseph Rosen in Dartmouth University (USA) helped us complete this study. I would like to thank assistance of our three research assistants in the Orthopaedic Department at National Hospital for Paediatrics, Dr. Le Tuan Anh, Dr Phung Cong Sang, and Dr. Hoang Hai Duc are greatly appreciated in general assistance in manuscript preparation.

\section{REFERENCES}

[1] R. Dee, L. C. Hurest, M. A. Gruber and S. A. Kottmeier, "Principles of Orthopedic Practice," 2nd Edition, McGrawHill, New York, 1997, pp. 699-716.

[2] H. A. T. Fairbank, "Congenital Dislocation of the Hip: With Special Reference to the Amlatomy,” British Jour- 
nal of Surgery, Vol. 17, No. 67, 1930, pp. 380-416. doi:10.1002/bjs. 1800176705

[3] N. H. Harris, G. C. Lloyd-Roberts and R. Gallien, “Acetabular Development in Congenital Dislocation of Hip," The Journal of Bone \& Joint Surgery, Vol. 57, No. 1, 1957, pp. 46-52.

[4] R. B. Salter, "Innominate Osteotomy in the Treatment of Congenital Dislocation and Subluxation of the Hip," The Journal of Bone \& Joint Surgery, Vol. 43, No. 3, 1961, pp. 518-539.

[5] B. Gulman, I. C. Tuncay, N. Dabak and N. Karaismailoglu, "Salter's Innominate Osteotomy in the Treatment of Congenital Hip Dislocation: A Long-Term Review," Journal of Pediatric Orthopaedics, Vol. 14, No. 5, 1994, pp. 662-666. doi:10.1097/01241398-199409000-00021

[6] C. Morin, G. Rabay and G. Morel, "Retrospective Review at Skeletal Maturity of the Factors Affecting the Efficacy of Salter's Innominate Osteotomy in Congenital Dislocated, Subluxed, and Dysplastic Hips,” Journal of Pediatric Orthopaedics, Vol. 18, No. 2, 1998, pp. 246-253. doi:10.1097/01241398-199803000-00022

[7] W. P. McCluskey, G. S. Bassett, G. Mora-Garcia and G. D. MacEwen, "Treatment of Failed Open Reduction for Congenital Dislocation of the Hip," Journal of Pediatric Orthopaedics, Vol. 9, No. 6, 1998, pp. 633-639. doi:10.1097/01241398-198911000-00001

[8] S. M. Hsiech and S. C. Huang, "Treatment of Developmental Dysplasia of the Hip after Failed Open Reduction," Journal of the Formosan Medical Association, Vol. 97, No. 11, 1998, pp. 763-769.

[9] B. G. Smith, M. B. Millis, D. Jaramillo, J. R. Kasser and L. A. Hey, "Post Reduction Computed Tomography in Developmental Dislocation of the Hip. Part I, Analysis of Measurment Reliability,” Journal of Pediatric Orthopaedics, Vol. 17, No. 5, pp. 626-230.

[10] M. M. El-Sayed, "Single-Stage Open Reduction, Salter Innominate Osteotomy, and Proximal Femoral Osteotomy for the Management of Developmental Dysplasia of the Hip in Children between the Ages of 2 and 4 Years," Journal of Pediatric Orthopaedics B, Vol. 18, No. 4, 2009, pp. 188-196. doi:10.1097/BPB.0b013e32832bf618

[11] C. E. Badgley, "Correlation of Clinical and Anatomical Facts Leading to a Conception of Etiology of Congenital Hip Dysplssias,” The Journal of Bone \& Joint Surgery, Vol. XXV, No. 3, 1943, pp. 503-523.

[12] M. Georges, "The Treatment of Congenital Dislocation and Subluxation of the Hip in the Older Child," Acta Orthopaedica Scandinavica, Vol. 46, No. 3, 1975, pp. 364399.

[13] J. O. Tavares and K. Molinero, "Elevation of Medial Tibial Condyle for Severe Tibia Vara,” Journal of Pediatric Orthopaedics B, Vol. 15, No. 5, 2006, pp. 362-369. doi:10.1097/01202412-200609000-00011

[14] L. T. Staheli, D. May and J. I. Tuei, "The Effect of the Inverted Limbus on Closed Management of Congenital Hip Dislocation,” Clinical Orthopaedics, Vol. 137, 1978, pp. 163-166.

[15] D. Tönnis, "Review of the Literature on Open Reduction of the Hip in Congenital Dysplasia and Dislocation of the Hip in Children and Adults,” In: D. Tönnis, Ed., Die Angeborene Huftdysplasie und Huftluxation im Kindes- und Erwachsenenalter, Springer, Berlin Heidelberg New York, 1987, pp. 332-342.

[16] S. Kleinberg and H. S. Lieberman, "The Acetabular Index in Infants in Relation to Congenital Dislocation of the Hip,” Archives of Surgery, Vol. 32, No. 6, 1936, pp. 10491054. doi:10.1001/archsurg.1936.01180240137007

[17] M. M. M. Napoli, A. A. Netto, C. Suguimoto and L. T. Takedo, "Anteversão dos Colos Femorais: Estudo Radiológico,” Revista da Imagem, Vol. 7, 1985, pp. 111-116.

[18] C. T. Ryder and L. Crane, "Measuring Femoral Anteversion: The Problem and a Method," The Journal of Bone \& Joint Surgery, Vol. 35, No. 2, 1953, pp. 321-328.

[19] A. McSweeny, "A Study of Femoral Torsion in Children," The Journal of Bone \& Joint Surgery, Vol. 53-B, No. 1, 1971, pp. 90-95.

[20] M. B. Dobbs and J. A. Morcuende, "Other Condition of the Hip,” In: W. W. Lowell and R. B. Winter, Ed., Pediatric Orthopedics, Philadelphia, London, New York, J.B. Lippincott Company, 1986, pp. 1126-1148.

[21] A. K. Mootha, R. Saini, M. S. Dhillon, S. Aggarwal, V. Kumar and S. K. Tripathy, "MRI Evaluation of Femoral and Acetabular Anteversion in Developmental Dysplasia of the Hip: A Study in an Early Walking Age Group," Acta Orthopaedica Belgica, Vol. 76, No. 2, 2010, pp. 174-180.

[22] D. Tönnis and A. Heinecke, "Acetabular and Femoral Anteversion: Relationship with Osteoarthritis of the Hip," The Journal of Bone \& Joint Surgery, Vol. 81-A, No. 12, 1999, pp. 1747-1770.

[23] B. McKibbin, "Anatomical Factors in the Stability of the Hip Joint in the Newborn,” The Journal of Bone \& Joint Surgery, Vol. 52-B, No. 1, 1970, pp. 148-159.

[24] A. Kalamchi and G. D. MacEwen, "Vascular Necrosis Following Treatment of Congenital Dislocation of the Hip,” The Journal of Bone \& Joint Surgery, Vol. 62, No. 6, 1980, pp. 876-888.

[25] R. B. Salter and J. P. Dubos, "The First Fifteen Years' Personal Experience with Innominate Osteotomy in the Treatment of Congenital Dislocation and Subluxation of the Hip,” Clinical Orthopaedics, Vol. 98, 1974, pp. 72 103. doi:10.1097/00003086-197401000-00009

[26] W. W. Tomford, "Transmission of Disease through Transplantation of Musculoskeletal Allografts,” The Journal of Bone \& Joint Surgery, Vol. 77, No. 11, 1995, pp. 17421754.

[27] D. H. Sutherland and R. Greenfield, "Double Innominate Osteotomy,” The Journal of Bone \& Joint Surgery, Vol. 59-A, No. 8, 1977, pp. 1082-1091.

[28] W. P. Barrett, L. T. Staheli and D. E. Chew, "The Effectiveness of the Salter Innominate Osteotomy in the Treatment of Congenital Dislocation of the Hip,” The Journal of Bone \& Joint Surgery, Vol. 68, No. 1, 1986, pp. 79-87.

[29] W. P. McCluskey, G. S. Bassett, G. Mora-Garcia and G. D. MacEwen, "Treatment of Failed Open Reduction for 
Congenital Dislocation of the Hip," Journal of Pediatric Orthopaedics, Vol. 9, No. 6, 1989, pp. 633-639. doi:10.1097/01241398-198911000-00001

[30] D. L. J. Trevor and J. A. Fixen, "Acetabuloplasty in the Treatment of Congenital Dislocation of the Hip," The Journal of Bone and Joint, Vol. 57-B, No. 2, 1975, pp. 167-174.

[31] J. K. Kessler, P. M. Stevens, J. T. Smith and K. L. Carroll, "Use of Allografts in Pemberton Osteotomies," Journal of Pediatric Orthopaedics, Vol. 21, No. 4, 2001, pp. 468473. doi:10.1097/01241398-200107000-00011

[32] J. S. Grudziak and W. T. Ward, "Dega Osteotomy for the Treatment of Congenital Dysplasia of the Hip," The Journal of Bone \& Joint Surgery, Vol. 83, No. 6, 2001, pp. 845-854.

[33] W. J. Wade, T. S. Alhussainan, A. Z. Zayed, N. Hamdi and D. Bubshait, "Contoured Iliac Crest Allograft Interposition for Pericapsular Acetabuloplasty in Developmental Dislocation of the Hip: Technique and Short-Term Results,” Journal of Children's Orthopaedics, Vol. 4, No. 5, 2010, pp. 429-438. doi:10.1007/s11832-010-0282-6

[34] R. Warndorf, "The Pathology amid Therapy of Congenital Dislocations of the Hip," American Journal of Orthopedic Surgery, Vol. 10, 1912, pp. 241-261.

[35] R. A. Hibbs, "Anteversion of the Neck of the Femur in Correction with Congennital Dislocationn of the Hip," The Journal of the American Medical Association, Vol. 65, 1916, pp. 1801-1802.

[36] A. Krida, P. C. Clonna and F. J. Carr, "Analysis of Results of Early Treatment of Congenital Dislocation of the Hip by Manipulation and Osteoclasis for Anterior Distortion,” The Journal of Bone \& Joint Surgery, Vol. 18, No. 4, 1936, pp. 1018-1029.

[37] H. R. McCarroll and C. H. Crego, "Primary Anterior Congenital Dislocation of the Hip," The Journal of Bone \& Joint Surgery, Vol. 21, No. 3, 1939, pp. 648-664.

[38] W. K. Massie and M. B. Howorth, "Congenital Dislocationn of the Hip. Part II. Results of Open Reduction as Seen in Early Adult Period,” The Journal of Bone \& Joint Surgery, Vol. 33, No. 1, 1951, pp. 171-190.

[39] D. M. Dunn and B. Notley, "Anteversion of the Neck of the Femur. A New Method of Measurement," The Journal of Bone \& Joint Surgery, Vol. 34, No. 2, 1952, pp. 181-186.

[40] H. A. Durham, "Anteversion of the Femoral Neck in the Normal Femur and Its Relation to Congenital Dislocation of the Hip," The Journal of American Medical Association, Vol. 65, No. 3, 1915, pp. 223-224. doi:10.1001/jama.1915.02580030015006

[41] W. N. Sankar, C. R. Young, A. G. Lin, S. A. Crow, K. D. Baldwin and C. F. Moseley, "Risk Factors for Failure After Open Reduction for DDH: A Matched Cohort Analysis,” Journal of Pediatric Orthopaedics, Vol. 31, No. 3, 2011, pp. 232-239. doi:10.1097/BPO.0b013e31820c9b31

[42] B. P. Farrell, H. L. Von Laskum and A. D. Smith, "Congenital Dislocation of the Hip. A Report of Three Hundred and Ten Cases Treated at the Nework Orthopaedic
Dispensary and Hospital," The Journal of Bone \& Joint Surgery, Vol. 8, No. 3, 1926, pp. 551-561.

[43] A. Lorenz, "Some Remarks on the Treatment and afterTreatment of Congenital Dislocation of the Hip," American Journal of Orthopedic Surgery, Vol. 2, No. 3, 1905, pp. 219-233

[44] E. H. Bradford, "The Treatment of Congenital Dislocatiomn of the Hip,” The Journal of Bone \& Joint Surgery, Vol. 5, No. 1, 1923, pp. 76-98.

[45] R. Soutter and R. W. Lovett, "Congenital Dislocation of the Hip. A Study of Two Hundred and Twenty-seven Dislocations," The Journal of American Medical Association, Vol. 82, No. 3, 1924, pp. 171-177. doi:10.1001/jama.1924.02650290001001

[46] E. L. Compere and W. J. Schnute, "Treatment of Congenital Dislocation of Tine Hip,” The Journal of Bone \& Joint Surgery, Vol. 28, 1946, pp. 555-564.

[47] S. Kumar and A. K. Jain, “Open Reduction of Late Unreduced Traumatic Posterior Hip Dislocation in Children,” Acta Orthopaedica, Vol. 70, No. 6, 1999, pp. 599602. doi:10.3109/17453679908997849

[48] F. H. Albee, "The Bone Graft Wedge. Its Use in the Treatment of Relapsing, Acquired, and Congenital Dislocation of the Hip,” New York Medical Journal, Vol. 102, 1915, pp. 433-438.

[49] T. A. Malvitz and S. L. Weinstein, “Closed Reduction for Congenital Dysplasia of the Hip: Functional and Radiographic Results after an Average of Thirty Years," The Journal of Bone \& Joint Surgery, Vol. 76, No. 12, 1994, pp. 1777-1792.

[50] S. L. Weinstein, S. J. Mubarak and D. R. Wenger, "Developmental Hip Dysplasia and Dislocation: Part II," The Journal of Bone \& Joint Surgery, Vol. 85, No. 1, 2003, pp. 2024-2035.

[51] J. C. Adam, "Standard Orthopedic Operation," 3rd Edition, Churchill Livingstone, Edinburgh, 1985.

[52] R. L. Marafioti and G. W. Westin, "Factors Influencing the Results of Acetabuloplasty in Children,” The Journal of Bone \& Joint Surgery, Vol. 62, No. 1, 1980, pp. 765769.

[53] C. J. Lin, Y. T. Lin and K. A. Lai, "Intraoperative Instability for Developmental Dysplasia of the Hip in Children 12 to 18 Months of Age as a Guide to SALTER Osteotomy,” Journal of Pediatric Orthopaedics, Vol. 20, No. 5, 2000, pp. 575-578. doi:10.1097/01241398-200009000-00006

[54] P. Bohm and A. Brzuske, "Salter Innominate Osteotomy for the Treatment of Developmental Dysplasia of the Hip in Children: Results of Seventy-Three Consecutive Osteotomies after Twenty-Six to Thirty-Five Years of Follow-Up,” The Journal of Bone \& Joint Surgery, Vol. 84 , No. 1, 2002, pp. 178-186.

[55] H. Ito, H. Ooura, M. Kobayashi and T. Matsuno, "Middle-Term Results of Salter Innominate Osteotomy," Clinical Orthopaedics \& Related Research, Vol. 387, pp. 156-164. doi:10.1097/00003086-200106000-00021

[56] H. Z. Herold, "Salvage Operations for Failure of Previ- 
ous Surgery in Congenital Dislocation of the Hip,” Israel Journal of Medical Sciences, Vol. 19, No. 9, 1983, pp. 824-827.

[57] C. F. A. Bos and T. J. Slooff, "Treatment of Failed Open Reduction for Congenital Dislocation of the Hip," Acta Orthopaedica, Vol. 55, No. 5, 1984, pp. 531-535. doi:10.3109/17453678408992953

[58] S. M. Hsiech, S. C. Huang, "Treatment of Developmental Dysplasia of the Hip after Failed Open Reduction,” Journal of the Formosan Medical Association, Vol. 97, No. 11, 1998, pp. 763-769.

[59] S. Chidambaram, A. R. Abd Halim, J. K. Yeap and S. Ibrahim, "Revision Surgery for Developmental of the Hip,” Medical Journal of Malaysia, Vol. 60, Suppl. C, 2006, pp. 91-98.

[60] E. Rafael, "Congenital Dislocation of the Hip. A Review and Assessment of Results of Treatment with Special Reference to Frame Reduction as Compared with Manipulative Reduction,” The Journal of Bone \& Joint Surgery, Vol. 42, No. 2, 1960, pp. 253-263.

[61] R. K. Ashley, L. J. Larsen and P. M. James, "Reduction of Dislocation of the Hip in Older Children," The Journal of Bone \& Joint Surgery, Vol. 54, No. 1, 1972, pp. 545550.

[62] R. B. Salter, J. Kostuik and S. Dallas, "Avascular Necrosis of the Femoral Head as a Complication of Treatment for Congenital Dislocation of the Hip in Young Children: A Clinical and Experimental Investigation,”
Canadian Journal of Surgery, Vol. 12, No. 1, 1969, pp. 44-61.

[63] J. R. Gager and R. B. Winter, "Avascular Necrosis of the Capital Femoral Epiphysis as a Complication of Closed Reduction of Congenital Dislocation of the Hip. A Critical Review of Twenty Years' Experience at Gillette Children's Hospital," The Journal of Bone \& Joint Surgery, Vol. 54 , No. 1, 1972, pp. 373-388.

[64] J. R. Buchanan, R. B. Greer III and J. M. Cotler, "Management Strategy for Prevention of Avascular Necrosis during Treatment of Congenital Dislocation of the Hip," The Journal of Bone \& Joint Surgery, Vol. 63, No. 1, 1981, pp. 140-146.

[65] M, Domzalski and M. Snyder, “Avascular Necrosis after Surgical Treatment for Developmental Dysplasia of the Hip,” International Orthopaedics, Vol. 28, No. 2, 2004, pp. 65-68. doi:10.1007/s00264-003-0522-1

[66] M. Subasi, H. Arslan, O. Cebesoy, A. Buyukbebeci, and A. Kapukaya, "Outcome in Unilateral Orbilateral DDH Treated with One-Stage Combined Procedure,” Clinical Orthopaedics and Related Research, Vol. 466, No. 4, 2008, pp. 830-836. doi:10.1007/s11999-008-0162-2

[67] C. M. Sullivan, D. K. Yousefzadeh, K. M. Doerger, T. E. BenAmi, "Doppler Ultrasound Evaluation of Perfusion of Femoral Head Cartilage after Reduction of Dislocated Hip in Developmental Dislocation of the Hip," Proceedings of the Pediatric Orthopaedic Society of North America 1997 Annual Meeting, Banff, 15 May 1997, pp. 15-17. 